\title{
DC Fault Study of a Point-to-Point HVDC System Integrating Offshore Wind Farm using High-Temperature Superconductor DC Cables
}

\author{
Wang Xiang, Member, IEEE, Weijia Yuan, Senior Member, IEEE, Lie Xu, Senior Member, IEEE, \\ Eoin Hodge, John Fitzgerald, Paul McKeever, Keith Bell, Member, IEEE
}

\begin{abstract}
This paper presents a feasibility study of an offshore wind farm (OWF) HVDC integration system using hightemperature superconductor (HTS) DC cables. A representative $\pm 100 \mathrm{kV} / 2 \mathrm{GW}$ point-to-point OWF HVDC system is proposed including HTS DC cables and two converter stations using modular multilevel converters (MMCs). To be compatible with the high current rating of the HTS cables, each of the offshore and onshore converter stations consists of three MMCs in parallel. To study the interaction between HTS DC cables and MMCs, a multiple lumped $\pi$-section model of a HTS DC cable considering electrical and thermal functionality is developed. This paper provides a critical assessment of the proposed HVDC-HTS system, with emphasis on the performance under fast DC fault transients. Detailed simulations presented in this paper reveal that the HVDC-HTS system provides effective current limiting against DC cable short circuit faults.
\end{abstract}

Index Terms-DC fault, HVDC transmission, high temperature superconducting, modular multilevel converter, renewable energy, wind energy.

\section{INTRODUCTION}

The issues of global warming and climate change have boosted the requirement for renewable energy. Recently, both the United Kingdom and the European Commission have set targets for net-zero greenhouse gas emissions by 2050 with requirements for carbon-neutral or even carbon-negative electricity supply. As part of the pathway towards that goal, the UK government aims to have $40 \mathrm{GW}$ of offshore wind farm (OWF) capacity operational by 2030 . To achieve this, offshore wind power transmission using modular multilevel converter (MMC) based high-voltage direct current (HVDC) technology will play an important role and has supplanted 2- or 3-level voltage source converter (VSC) as the standard form of HVDC converter adopted by industry [1]-[3]. Up to the time of writing, more than ten MMC-HVDC projects have been commissioned globally to integrate OWFs [4].

With the increased scale of OWFs, the needs for 5 to $20 \mathrm{GW}$ Pan-European transmission corridors and HVDC transmission at higher power rating (e.g. $2 \mathrm{GW}$ per connection) are emerging. However, conventional HVDC cables are limited in terms of

This work is sponsored by the collaboration project between SuperNode and the Offshore Renewable Energy Catapult (OREC) as part of the research programme of the OREC Electrical Infrastructure Research Hub. (Corresponding author: Wang Xiang)

W. Xiang, W. Yuan, L. Xu, K. Bell are with the Department of Electronic and Electrical Engineering, University of Strathclyde, G1 1XW, Glasgow, UK. (e-mail: xiangwang1003@foxmail.com, weijia.yuan@strath.ac.uk, lie.xu@strath.ac.uk, keith.bell@strath.ac.uk).

E. Hodge, J. Fitzgerald are with the SuperNode, Belfield, Dublin 4, Ireland. (e-mail: eoin.hodge@supernode.energy,john.fitzgerald@supernode.energy).

P. McKeever is with the Offshore Renewable Energy Catapult (OREC), Blyth, Northumberland, NE24 1LZ, UK. (e-mail: paul.mckeever@) ore.catapult.org.uk). current levels which in turn, limits their power transfer capability (e.g. $700 \mathrm{MW}$ per cable). For this reason, to develop large-scale offshore DC networks, large numbers of DC cables will be required, which are costly, difficult to install and have a significant environmental footprint, an issue of particular sensitivity for when cables are brought onshore [5]-[7]. To increase power transfer capacity, ultra-high voltage HVDC cables (above $600 \mathrm{kV}$ ) are being developed, but these ultra-high voltages will increase electrical insulation cost and the footprint of converter stations which will have a major impact on cost, particularly for stations on offshore platforms.

One promising solution proposed to address this challenge is to adopt the second-generation high-temperature superconductor (HTS) cables [8][9]. The HTS DC cables have the merits of a very high current capacity, smaller overall size, and higher efficiency. Several superconducting materials are now commercially available at an increasingly affordable price for HTS applications and industrial manufacture [10]-[15].

In reference [11], $1 \mathrm{~km}$ of HTS DC power cable is installed in the $80 \mathrm{kV} / 60 \mathrm{MW}$ Hanlim line commutation converter (LCC) based HVDC system. Steady-state and DC fault transient studies were carried out on the system. Owing to the current control and the voltage-dependent current limiter (VDCOL) of the LCC rectifier and the unidirectional conduction of the LCC inverter, it was found that the peak value of DC overcurrent was lower than the critical current of the HTS DC cable. Thus, quenching did not occur and the HTS DC power cable was safe during DC faults. A prototype of $100 \mathrm{~m} / 3.25 \mathrm{kA} / 80 \mathrm{kV}$ HTS DC cable was further developed in South Korea and successfully passed the qualification tests [12]. Reference [13] simulated an LCC-HVDC transmission system incorporating a $300 \mathrm{~km}$ HTS DC cable, where the HTS DC cable resistance was modeled using a pre-defined piece-wise function of time. Similar to [11], reference [13] also showed that the HTS based LCC-HVDC system can effectively limit the fault currents during DC faults, thereby, providing self-protection capability.

Reference [14] simulated replacement of the line commutation converter in [11] by a two-level voltage source converter. The two-level VSCs and HTS DC cables are modeled using a Real-Time Digital Simulator (RTDS). The steady-state analysis results revealed that the harmonic current generated by VSCs causes an AC power loss in the HTS DC power cable. However, no DC fault studies were reported in [14]. Reference [15] studied the control and modeling of a fourterminal VSC-HVDC system based on HTS DC cables, in which the HTS DC cables were modeled using geometry characteristics provided by the Electric Power Research Institute (EPRI). However, this model is not generic and cannot be applied to HTS DC cables with other design configurations. Reference [16] undertook an economic evaluation of 
integration with OWFs. It is shown that a two-stage DC collector grid, which consists of a $\pm 2.5 \mathrm{kV}$ cluster collector network using conventional DC cables and $\mathrm{a} \pm 20 \mathrm{kV}$ wind park collector network using HTS DC cables, together with a \pm 150 $\mathrm{kV}$ HTS HVDC transmission system offers reduced losses and is cost-competitive with respect to AC connection systems. In June 2019, it was reported that the Nexans company successfully completed qualification tests on a $30 \mathrm{~m} / 10 \mathrm{kA} / 320 \mathrm{kV}$ HTS cable, which was developed as part of the EU-funded Best Paths project [17].

As can be seen from the above literature review above, most of the existing publications focus on the steady-state, DC fault transient studies and qualification tests of the HTS DC cables dedicated to LCC and two-level VSC HVDC systems. None of them reported on a feasibility study for a modular multilevel converter (MMC) based HTS HVDC system, which is the mainstay of converter topology in OWF integration applications. To address this challenge, this paper proposes a point-to-point MMC-HVDC system using high-temperature superconductor DC cables to integrate the offshore wind power and aims at investigating the technical feasibility of HTS DC cable applications in the MMC-HVDC system. The paper has three contributions:

- A half-bridge modular multilevel converter (MMC) and HTS DC cable-based point-to-point HVDC system, capable of transmitting $2 \mathrm{GW}$ of offshore wind power at $\pm 100 \mathrm{kV}$ DC voltage is designed.

- A generic lumped HTS cable model considering both the electrical and thermal functionalities is developed dedicated to power system studies. Modeling using multiple $\pi$ sections of HTS DC cables is also evaluated.

- Steady-state and DC fault transient analysis for the overall model is performed, providing a guidance for future practical applications.

The remainder of the paper is organized as follows. Section II describes the overall layout of the OWF MMC-HVDC systems using HTS DC cables. Section III presents the modeling methodologies for the MMC and HTS DC cable and discusses the performance using a multiple lumped $\pi$-section model. The effectiveness of the proposed model as well as the DC fault transient studies are carried out in Section IV. Finally, conclusions are drawn in Section V.

\section{TOPOLOGY OF THE OWF HVDC System UsING HTS DC CABLES}

Fig. 1 depicts an envisaged symmetrical monopole $\pm 100 \mathrm{kV} / 2 \mathrm{GW}$ point-to-point OWF HVDC integration system using HTS DC cables, which consists of fully rated converter based wind turbines (WTs), half-bridge modular multilevel converter (HB-MMC) based offshore and onshore stations and a pair of $100 \mathrm{~km}$ HTS DC transmission cables.

The wind turbines are connected to the $66 \mathrm{kV}$ offshore $\mathrm{AC}$ network via fully-rated converters and step-up transformers. The $100 \mathrm{~km}$ HTS DC cables with 10kA current rating are used as positive and negative transmission lines. To be compatible with the high current rating of the HTS cables, each of the offshore and onshore converter stations consists of three MMCs in parallel connection at the DC side due to limited IGBT current capacity, as shown in Fig. 1. The DC voltage and power ratings of each $\mathrm{MMC}$ are $\pm 100 \mathrm{kV}, 700 \mathrm{MW}$ respectively. $F_{1}, F_{2}$,
$F_{3}$ represent the faults that occur at the head, the middle and the end of the HTS DC cable, respectively. $F_{4}$ represents the AC fault at the integration point of common coupling (PCC) of the grid side. These faults will be studied in later sections.

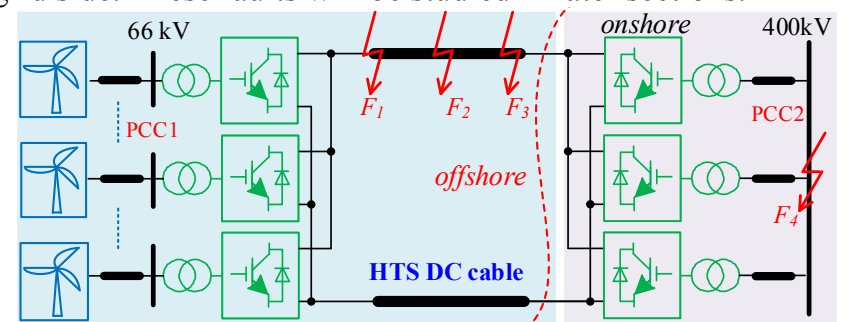

Fig. 1. The topology of the point-to-point OWF HVDC system using HTS DC cables.

\section{A. Topology of Half-Bridge Modular Multilevel Converter}

Fig. 2 shows the typical power circuit for a three-phase HBMMC, which consists of six arms, with each arm comprising of series-connected half-bridge (HB) submodules (SMs) and an arm inductor. Each phase-leg of the MMC comprises an upper arm and a lower arm, with each arm designed to block at least the full DC link voltage. Each HBSM is composed of two IGBT devices with antiparallel diodes and one DC capacitor, as shown in Fig. 2. In a high voltage rating MMC, each arm can contain hundreds of SMs, so a high number of voltage steps can be generated to resemble high-quality sinusoidal outputs with very low harmonic content.

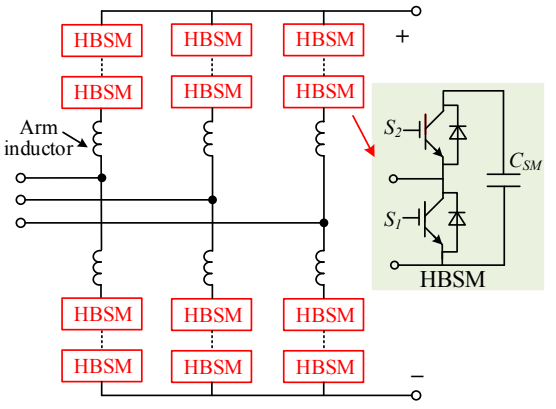

Fig. 2. Topology of the half-bridge modular multilevel converter.

\section{B. Configuration of HTS DC Cable}

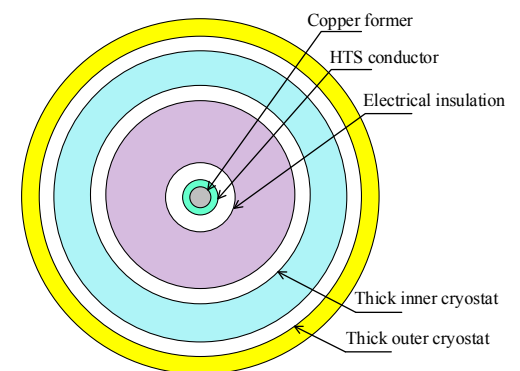

Fig. 3. Configuration of the cross-section of the HTS DC cable.

The cross-section of the 10kA HTS DC power cable is shown in Fig. 3. The cable core is composed of several layers of HTS tapes that are helically wound on a copper former. Polypropylene laminated paper (PPLP) based electric insulation is applied to the HTS tapes and the cable is operated at low temperature. The low operating temperature is maintained by the superconducting cable cooling system, which contains a cryostat with liquid nitrogen (LN2) feeding lines, operating at a temperature range of $65-77 \mathrm{~K}$. The LN2 circulates in the cable loop to provide a cooling source, as shown in Fig. 
3. A circulation pump is installed in the LN2 circulating loop to ensure a certain LN2 flow rate and pressure [10].

A commercially available second-generation (2G) HTS conductor coated in GdBCO material is considered in this paper. The operating temperature range of the tape is $67-77 \mathrm{~K}$.

The resistivity of the HTS tape is negligible during normal operating conditions. However, since the resistivity of HTS is significantly affected by the external applied current density and temperature, the situation becomes complicated for the transient state in which a fault occurs. If the fault current exceeds the critical current, the majority of the conductor current will be diverted into the copper stabilizer layer of the conductor and the superconductor (SC) will enter the quenching state and lose superconductivity. The critical current of the GdBCO conductor is highly dependent on the applied magnetic field. Fig. 4 depicts the critical current of GdBCO tapes versus the applied magnetic field. As can be seen, the critical current (or critical current density) decreases with the increase in the magnetic field, and the critical current decreases drastically when the applied magnetic field is larger than 1T.

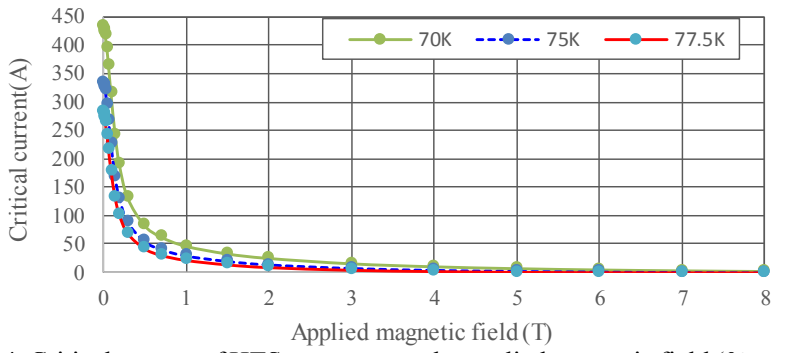

Fig. 4. Critical current of HTS tapes versus the applied magnetic field $\left(0^{\circ}\right.$ angle).

\section{MODELING OF AN OWF HVDC SYSTEM USING HTS DC CABLE}

To facilitate electromagnetic DC fault transient studies, the OWF MMC-HVDC system will be modeled in PSCAD/ EMTDC.

\section{A. Modeling of the $M M C$}

As shown in Fig. 1, the offshore and onshore converter stations contain six MMCs, which are composed of thousands of SMs. Using detailed switching IGBT devices to model the overall system will be extremely time-consuming. For systemlevel studies, the internal dynamics of SMs are less critical, so the arm-switching averaged value model (AVM) of HB-MMCs is used to reduce the computation burden [18][19].

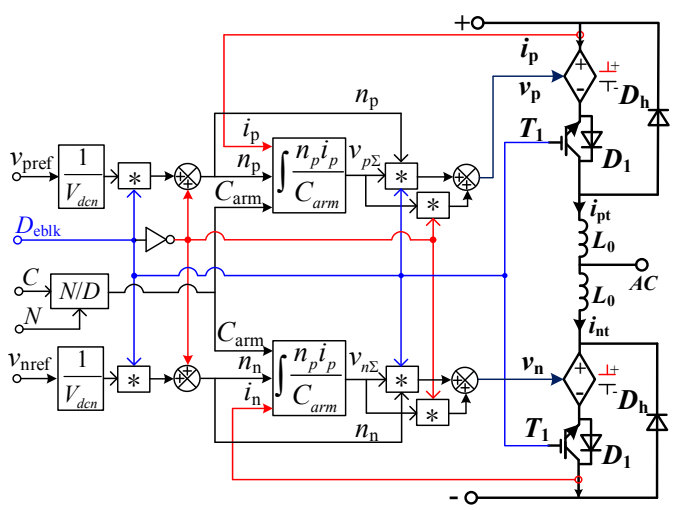

Fig. 5. Averaged value model (AVM) of MMC (single-phase view).
A per-phase representation of an AVM of a three-phase MMC is shown in Fig. 5. In the AVM approach, the SM capacitors on each arm are represented by one single equivalent capacitor, and the voltage generated by each arm is represented by a controllable voltage source. To accurately mimic the typical MMC behavior when all its switches are blocked, i.e., all the IGBTs in the SMs are switched or gated off, additional diodes and IGBTs are considered in the AVM, e.g., $T_{l}, D_{l}, D_{h}$ in Fig. 5. Hence, the AVM can effectively simulate the normal operation and blocking states of the MMC.

\section{B. Accuracy of AVM of $H B-M M C$}

The accuracy of the arm-switching AVM model is well studied in [20]. According to [20], the DC fault responses of the arm-switching AVM model and the detailed IGBT-based model are identical.

To further evaluate the accuracy, typical point-to-point $\pm 320 \mathrm{kV} / 1000 \mathrm{MW}$ MMC-HVDC systems based on the AVM model and the detailed IGBT-based model are built, respectively. To reduce computation burden, each arm contains 20 SMs. The fault currents of the AVM model $\left(I_{d c A V M}\right)$ and the detailed IGBT-based model $\left(I_{d c D E T}\right)$ are depicted in Fig. 6 . The DC pole-to-pole fault is applied at $1.5 \mathrm{~s}$. As can be seen, the AVM model complies with the detailed IGBT-based model well, which validates that the accuracy of the AVM model is acceptable even within the millisecond range.

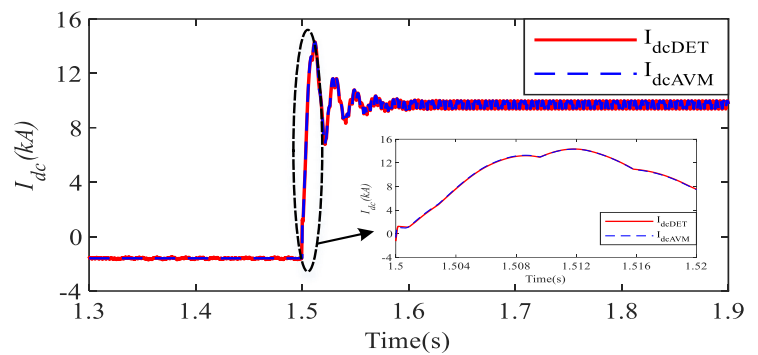

Fig. 6. Comparison of DC currents between the AVM model and the detailed IGBT-based model.

\section{Modeling of the HTS DC Cable}

For the HTS DC cable model, a lumped model with several $\pi$-section segments is developed in this paper, as shown in Fig. 7. Each $\pi$-section consists of the resistance, inductance and capacitance of the cable segment, where the capacitance and inductance per kilometer of the designed HTS cable are $0.076 \mu \mathrm{F} / \mathrm{km}$ and $1.45 \mathrm{mH} / \mathrm{km}$, respectively. Considering that there are pumping and re-cooling stations along the cable, the temperature variations along each section are ignored. Thus, the resistance of each $\pi$-section depends on its operating temperature and the current flowing through the segment, which will be calculated in the following context.

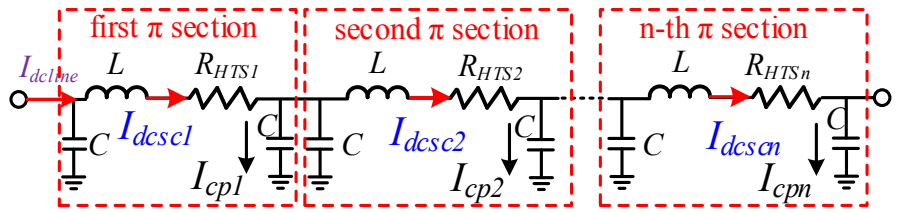

Fig. 7. Multiple $\pi$-section lumped model of the HTS DC cable.

The critical temperature, critical current and working magnetic field are important variables that directly determine the resistivity of HTS tape. Mathematically, the temperature dependence of the critical current density of HTS tapes is 
described as:

$$
J_{c}(T)=\left\{\begin{array}{cl}
J_{c 0}(B)\left(\frac{T_{c}-T}{T_{c}-T_{0}}\right)^{\alpha}, & T_{0}<T<T_{c} \\
0, & T>T_{c}
\end{array}\right.
$$

where $\alpha$ is the density exponent, which is conventionally equal to 1.5. $T_{c}$ and $J_{c}$ are the critical temperature and critical current density, respectively. $J_{c 0}$ is the critical current density at the initial temperature $T_{0}$ and the working magnetic field $B$ [21]. Equation (1) shows that, when the working temperature increases, the current density will be decreased accordingly. The current density of the GdBCO layer will be reduced to 0 if the temperature is above the critical temperature level.

When the applied current $I$ of the HTS tape is less than the critical current $I_{c}$ and its temperature $T$ is less than the critical temperature $T_{c}$, the superconductor is considered to be in the superconductive state. The resistivity of HTS tape $\rho_{s c}=0$ describes this state.

When $I>I_{c}$ and $T<T_{c}$, the GdBCO layer quenches, which results in the appearance of resistance. The highly non-linear relationship of the superconductor between the current and the voltage is described using the $E-J$ power law, and the resistivity of the superconductor can be calculated using:

$$
\rho_{s c}=\frac{E_{c}}{J_{c}(T)}\left(\frac{J}{J_{c}(T)}\right)^{N-1}, \quad T<T_{c}, \quad J>J_{c}
$$

where $E_{c}=1 \mu \mathrm{V} / \mathrm{cm}$ is the critical electrical field. The $N$-value is usually between 25 and 30 for GdBCO tapes. When the applied current is greater than the critical current, a joule heating effect occurs due to the exponential rise in $\rho_{\text {sc }}$, leading to the rise in temperature of the superconducting material.

When $T>T_{c}$, the GdBCO layer completely loses superconductivity and converts into a normal state. The applied current is then diverted into the copper stabilizer layer and the copper former. Thus, Joule heating occurs again in these coppers, resulting in a dramatic temperature rise. In this case, the resistivity of the superconductor is considered to be equal to the resistivity of the copper, which is a function of the temperature as expressed in the following equation:

$$
\rho_{\text {copper }}=(0.0084 T-0.4603) \times 10^{-8}, 77 \mathrm{~K}<T<250 \mathrm{~K}
$$

Then, the resistance $R_{H T S}$ of each $\pi$-section can be obtained as a piecewise function of the current $I$ and the temperature $T$, as shown below.

$$
R_{H T S}=R_{s c} / / R_{\text {copper }}=\left\{\begin{array}{crr}
0 & , T<T_{c}, & I<I_{c} \\
R_{s c} / / R_{\text {copper }}, T<T_{c}, & I>I_{c} \\
R_{\text {copper }}, T>T_{c} &
\end{array}\right.
$$

Equation (4) shows that the copper resistance is the dominant factor during flux flow and quenching states. Thus, the magnetic field dependence has little impact on the cable resistance during these states.

Based on the law of energy conservation, and assuming that there is no thermal exchange with the external environment, the heat generated by the superconductor is absorbed by the superconductor itself and the LN2 envelope. The heat that is absorbed by the superconductor results in an increase in the superconductor temperature. Assuming that there is no temperature variation in the LN2 envelope, since the duration of the fault current is quite small, the joule heating $P_{\text {diss }}(\mathrm{t})$ generated from the superconductor is expressed as:

$$
P_{\text {diss }}(t)=i(t)^{2} R_{H T S}(t)
$$

where $t$ is the time. The net power $P_{S C}(\mathrm{t})$ in the superconductor is:

$$
P_{S C}(t)=P_{\text {diss }}(t)-P_{\text {cooling }}(t)
$$

where $P_{\text {cooling }}$ is the power dissipated by LN2. It can be expressed as:

$$
P_{\text {cooling }}(t)=h * A *(T(t)-77)
$$

where $A$ is the surface area covered by the cooler and $h$ is the heat transfer coefficient depending on the temperature rise $(\Delta T)$.

Currently, there is no analytical expression for $h$ to represent the efficiency of removing the dissipated heating from the superconductor to the cryogenic envelope. But, in general, an empirical formula can be used according to [22]. In accordance with the approach used in [22] and combining (5)-(7), the temperature of the superconductor can be calculated as:

$$
T(t)=T_{0}+\frac{1}{C_{p H T S}} \int_{0}^{t} P_{S C}(t) d t
$$

where $C_{p H T S}(\mathrm{~J} / \mathrm{K})$ is the heat capacity of the material, which represents the number of joules generated per Kelvin degree. This amount depends on the specific heat capacity and the mass of the material of each layer. As the volume and specific heat capacity of each material in the tape are different, the heat capacity of each material is calculated individually by multiplying its specific heat value by the volume and the density of the material. In this paper, the heat capacities of PPLP insulation, the substrate layer, the stabilizer layer, the GdBCO layer and the copper former are considered [23].

The aforementioned thermal calculation process of HTS tapes is modeled in PSCAD/EMTDC by developing the userdefined components. Fig. 8 shows the flowchart of resistance calculation in PSCAD/EMTDC. Equations (1)-(8) are programmed in PSCAD. Once the cable current of the electrical circuit is updated, the new resistance and the temperature will be calculated in the next iteration. The duration of the iteration step is set based on the PSCAD/EMTDC circuit simulation time step; usually, $20-50 \mu$ s is used.

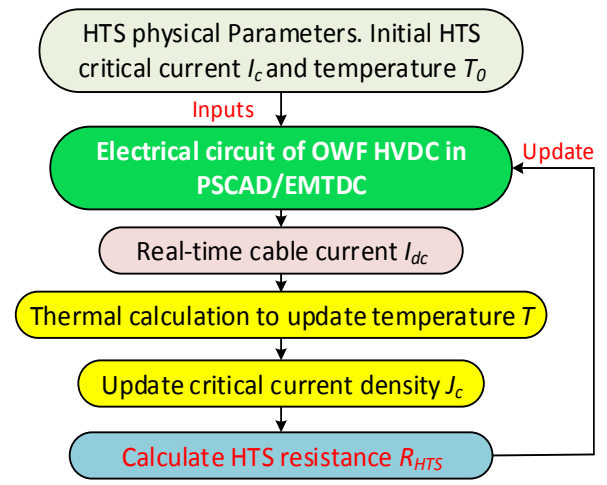

Fig. 8. Flowchart of the superconducting resistance calculation iteration in PSCAD/EMTDC.

D. Performance Evaluation of Multiple $\pi$-section Lumped Model of HTS DC Cable

To investigate the performance of the HTS DC cable model with different $\pi$ sections, initial tests where the cable is connected to a stiff DC system are carried out. The topology of 
the test system is shown in Fig. 9. As depicted, the tested HTS DC cable model is connected with a $100 \mathrm{kV}$ DC voltage source and a $10 \Omega$ resistive load. The switch $S_{f f t}$ is used to initiate the fault. The physical parameters of HTS tape are listed in TABLE I, including different layers of HTS tape and the electrical insulation [24]. Considering the pitch angle, the length of the HTS tapes is designed as $200 \mathrm{~km}$. In this section, the lumped models using one $\pi$-section, two $\pi$-section, five $\pi$-section and ten $\pi$-section equivalents to characterize the HTS DC cable are considered.

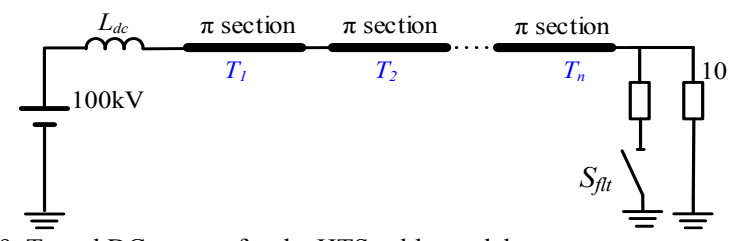

Fig. 9. Tested DC system for the HTS cable model.

TABLE I Parameters of the HTS DC cable

\begin{tabular}{|c|c|c|c|}
\hline \multicolumn{2}{|c|}{ Superconductor layer } & \multicolumn{2}{|c|}{ Stabilizer layer } \\
\hline Material & GdBCO & Number of tapes & 64 \\
\hline Number of tapes $/ \mathrm{N}_{\mathrm{s}}$ & 64 & Tape width & $4.4 \mathrm{~mm}$ \\
\hline Tape width & $4.4 \mathrm{~mm}$ & Layer thickness & $40 \mu \mathrm{m}$ \\
\hline ckness & $1 \mu \mathrm{m}$ & Length & $200 \mathrm{~km}$ \\
\hline Tape length & $200 \mathrm{~km}$ & Density & $8940 \mathrm{~kg} / \mathrm{m}^{3}$ \\
\hline Tape critical current at $77 \mathrm{~K}$ & $282 \mathrm{~A}$ & Heat capacity & $185(\mathrm{~J} / \mathrm{kg} . \mathrm{K})$ \\
\hline Critical temperature $T_{c}$ & $92 \mathrm{~K}$ & \multicolumn{2}{|c|}{ Substrate layer } \\
\hline Working temperature $T_{0}$ & $77 \mathrm{~K}$ & Material & Hastelloy \\
\hline Density & $7039 \mathrm{~kg} / \mathrm{m}^{3}$ & Tape width & $4.4 \mathrm{~mm}$ \\
\hline value of the & & Layer thickness & $60 \mu \mathrm{m}$ \\
\hline conducting & 30 & Length & $200 \mathrm{~km}$ \\
\hline нантат & & Density & $8910 \mathrm{~kg} / \mathrm{m}^{3}$ \\
\hline \multicolumn{4}{|c|}{ Insulation } \\
\hline Material & $\begin{array}{l}\text { PPLP } \\
\end{array}$ & Inner diameter & $25.8 \mathrm{~mm}$ \\
\hline length & $100 \mathrm{~km}$ & Outer diameter & $48 \mathrm{~mm}$ \\
\hline Density & $0.9 \mathrm{~kg} / \mathrm{m}^{3}$ & Heat capacity & 1930 (J/ kg.K) \\
\hline
\end{tabular}

A temporary DC short-circuit fault with $0.01 \Omega$ resistance is applied at the end of DC cable ( $F_{3}$ in Fig. 1$)$ by closing $S_{f f t}$ at $2 \mathrm{~s}$. The fault is then self-cleared after $20 \mathrm{~ms}$. Fig. 10 shows the superconductor temperature and the DC current $\left(I_{d c s i}\right.$ in Fig. 7, $i=1,2, \ldots, n)$ of each $\pi$ section of the four lumped models.

Since 64 tapes are used, the critical cable current is $18.05 \mathrm{kA}$. As can be seen from Fig. 10, once the DC cable current exceeds the critical current, the HTS tapes will enter the quenching state, resulting in high resistance and temperature. When the DC fault disappears, the superconductor will recover to the normal state and the temperatures recover to $77 \mathrm{~K}$, as shown in Fig. 10 (a)(d). For the models using five $\pi$ sections and ten $\pi$ sections, since the distances from each section to the fault location are different, the cable capacitor to ground discharging currents are different, leading to the different SC currents, as depicted in the zoomed-in waveforms of Fig. 10 (c)(d). Thus, there are slight differences in the $\mathrm{SC}$ temperatures and recovery time between each section. However, the tendencies of the temperature and the cable current waveforms of the four lumped models are almost the same.
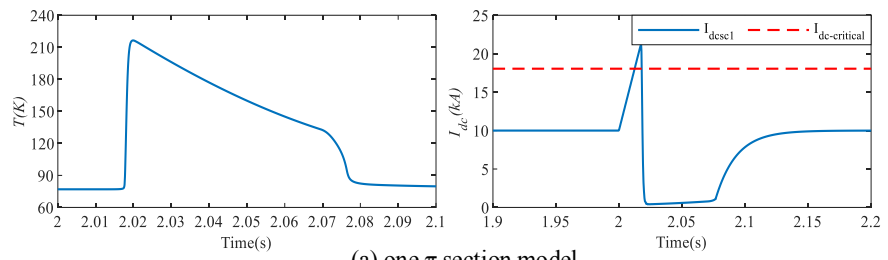

(a) one $\pi$ section model
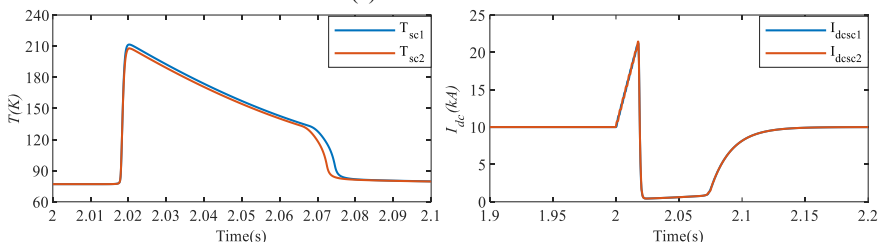

(b) two $\pi$ sections model
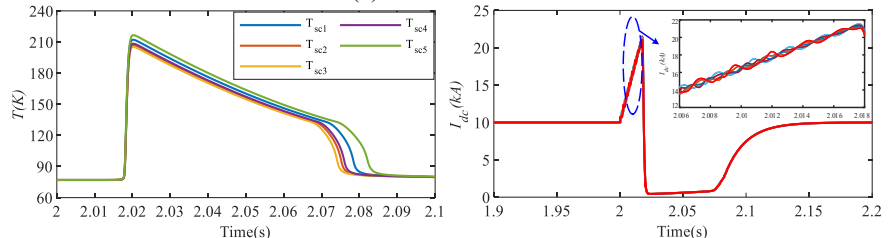

(c) five $\pi$ sections model
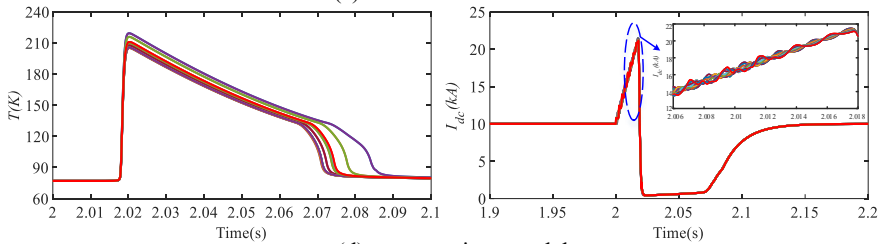

(d) ten $\pi$ sections model

Fig. 10. Simulation results of four lumped models under a temporary DC fault.

In cable-based HVDC systems, most of the DC faults are permanent. So permanent short-circuit faults with $0.01 \Omega$ resistance are applied at the end of DC cable at $2 \mathrm{~s}$. The SC temperature and the DC current of each $\pi$ section of the four studied lumped models are depicted in Fig. 11.

As can be seen in Fig. 11, once the DC current exceeds the critical current, the HTS tapes will enter the quenching state, resulting in high resistance and temperature. Under post-fault steady-state, the SC temperatures and the cable resistances are maintained at $169 \mathrm{~K}$ and $17 \Omega$ respectively.

To evaluate the accuracy of the four models, the HVDC currents $\left(I_{\text {dcline }}\right.$ in Fig. 7) of the four models are compared and are depicted in Fig. 12. As can be seen in the zoomed-in waveforms, the DC cable currents using two $\pi$ sections, five $\pi$ sections and ten $\pi$ sections are identical, which indicates that the accuracy of these models is the same from the perspective of the HVDC system.
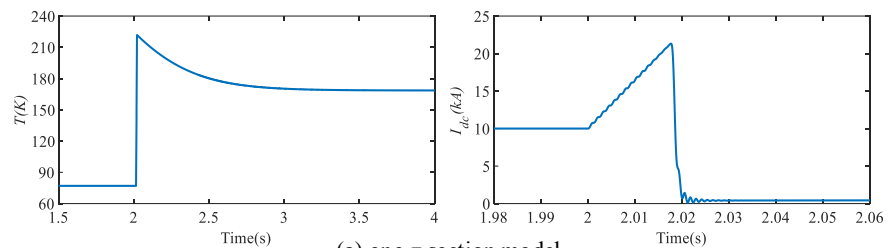

(a) one $\pi$ section model
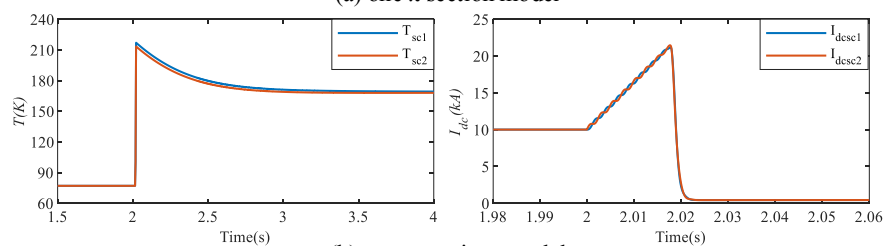

(b) two $\pi$ sections model 

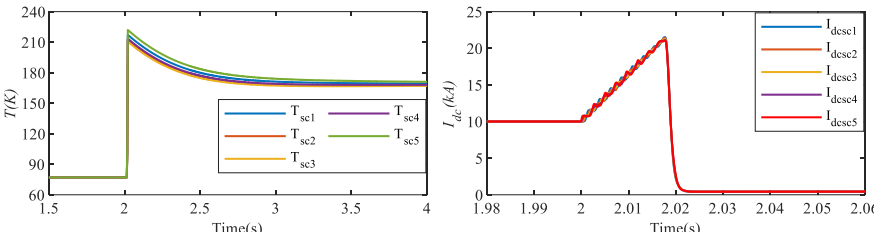

(c) five $\pi$ sections model

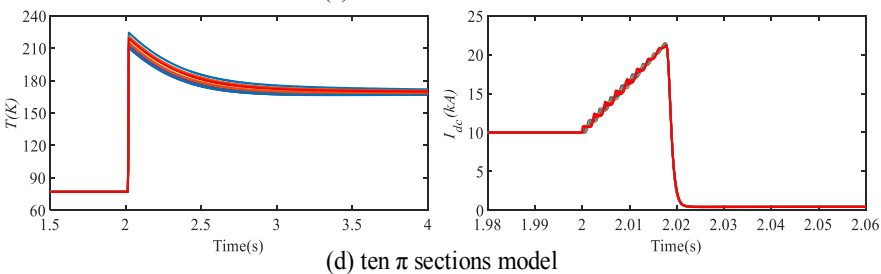

Fig. 11. Simulation results of four lumped models under a permanent DC fault.

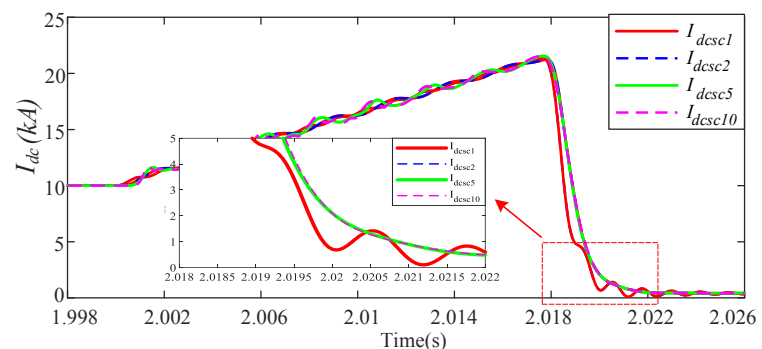

Fig. 12. Comparisons of DC cable currents of four models.

E. Suitability Using the Two $\pi$-section Lumped Model in Long Length HTS DC Cables

Based on the aforementioned analysis, it can be concluded that the two $\pi$-section lumped model is sufficient in this study due to the following reasons.

1) The key variable that couples the HVDC system and HTS cables is the DC cable current. As can be seen in Fig. 12, the DC fault current of the two $\pi$-section lumped model is the same as those using higher $\pi$ sections, which indicates that the two $\pi$ section lumped model is able to reflect the dynamics of fault current.

2) The HVDC system contains multiple converters. Although AVM models are adopted, the simulation speed will be very slow if the cable model with higher $\pi$ sections is adopted.

3 ) In reality for a $100 \mathrm{~km}$ length cable, there will inevitably be temperature differences along the cable length. However, in fault conditions, the MMC will be blocked and the $\mathrm{AC}$ circuit breakers will isolate the cables within tens of milliseconds. Therefore, using a lumped HTS cable model (as in this paper) or a finely distributed HTS cable model will not change the conclusions of this paper.

\section{F. Reliability of the HTS DC Cables}

The reliability of the high-temperature superconducting cable system depends on the reliability of the cable (layers, insulation and so on), the cooling system (temperature control), and the terminations (connecting the HTS cable to the cooling system). According to [25], the state-space model for reliability analysis can be obtained. By using fault-tree analysis, the failure rates and repair rates of each sub-system can be calculated. However, the commissioned HTS transmission power cable projects are very rare and the in-use time is short. It is difficult to collect the reliability data for the HTS cable system.

For the temperature control, the pumping and re-cooling stations are installed along the cable. To maintain reliability, there will be a redundant cooling system available in case the temperature of the cable is out of the working range [26]. Additionally, the cable insulation system is designed to passively maintain the cryogen temperature unpowered for 2 weeks, to facilitate corrective maintenance.

If there is a failure in the cooling system, the cable will not quench immediately because there are very small losses in DC operation compared to a relatively large cooling reservoir. Moreover, the redundant cooling system can automatically kick in when the main cooling system fails.

If a single cable is completely broken down, the power transmission will be interrupted in point-to-point HVDC systems. After maintenance, the power transmission can be recovered. While in the meshed HVDC grids, the faulty cable will be isolated by DC disconnectors. And the offshore wind power can be transferred through other cables in the meshed network.

Basically, with the development of manufacturing and the maturity of maintenance experience, the reliability can be further improved.

\section{DC FAUlt TRANSIENT ANALYSIS OF THE OWF HVDC SYSTEM USING HTS DC CABLE}

The MMC and HTS DC cable-based OWF HVDC system shown in Fig. 1 is modeled in PSCAD/EMTDC. The wind farm comprises type 4 wind turbines with full AC-DC-AC converters, which are modeled by one aggregated model. As justified in Section III.C, the HTS cables on the positive and negative poles adopt the two $\pi$-section lumped model. The MMCs in the offshore station operate in grid forming mode to establish the offshore $\mathrm{AC}$ voltage with controlled amplitude and constant frequency. The MMCs in the onshore station control the DC link voltage of the HVDC system. The main circuit parameters of the MMCs are listed in TABLE II.

To protect the converters from overcurrent during DC shortcircuit faults, overcurrent protection is implemented in each MMC. Once the arm current exceeds twice the rated value (6.6 kA in the simulation), the MMC will be blocked immediately. In conventional point-to-point HVDC systems, the AC circuit breakers (ACCBs) should be tripped to isolate the system from $\mathrm{AC}$ grids when DC faults occur. However, to investigate the progress of transients during $\mathrm{DC}$ faults, the operation of ACCBs is not considered in this paper.

\begin{tabular}{c|l|c}
\multicolumn{3}{c}{ TABLE II Parameters of each MMC. } \\
\hline \hline \multirow{2}{*}{ Parameters } & Values \\
\hline & Rated DC voltage & $\pm 100 \mathrm{kV}$ \\
& Rated capacity & $700 \mathrm{MVA}$ \\
& Arm inductance & $16 \mathrm{mH} / 0.15 \mathrm{pu}$ \\
& Number of SM per arm & 100 \\
& SM capacitance & $20 \mathrm{mF}$ \\
& Rated SM capacitor voltage & $2 \mathrm{kV}$ \\
\hline AC transformer & Turns ratio & $66 \mathrm{kV} / 110 \mathrm{kV}$ \\
(offshore) & Leakage inductance & $15 \%$ \\
\hline AC transformer & Turns ratio & $110 \mathrm{kV} / 400 \mathrm{kV}$ \\
(onshore) & Leakage inductance & $15 \%$ \\
\hline \hline
\end{tabular}

A. Performance under Wind Power Fluctuation

The results from the simulation of normal operation are shown in Fig. 13. From $2.5 \mathrm{~s}$ to $2.7 \mathrm{~s}$, the wind power ramps 
down from $1.6 \mathrm{GW}$ to $1.5 \mathrm{GW}$ and increases to the rated value of $2 \mathrm{GW}$ at $3.7 \mathrm{~s}$, as shown in Fig. 13 (a). Fig. 13 (b)-(d) show the HVDC current, the DC pole voltages of the offshore station and the root mean square (RMS) voltage of the PCC respectively. As can be seen, the DC pole voltages are well maintained at $\pm 100 \mathrm{kV}$ during wind power fluctuation.
Furthermore, the PCC RMS voltage is controlled at $66 \mathrm{kV}$ under steady-state. Fig. 13 (e)-(f) show the HTS resistances and temperatures of the two $\pi$ sections on the positive pole. They are kept as $0 \Omega$ and $77 \mathrm{~K}$ respectively, indicating that the HTS $\mathrm{DC}$ cables remain in superconducting state during wind power fluctuation.

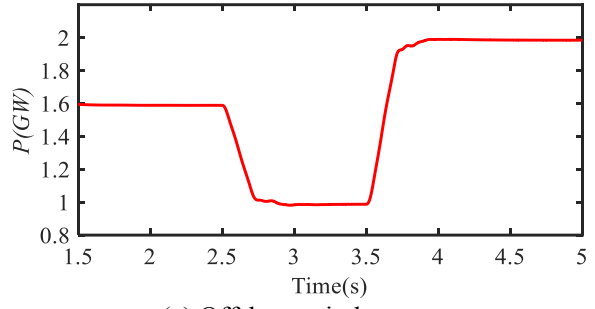

(a) Offshore wind power

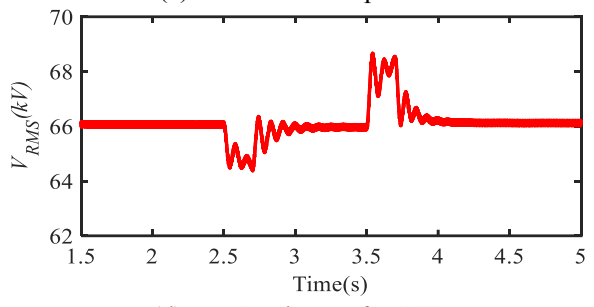

(d) RMS voltage of PCC1

Fig. 13. Normal operation during wind power fluctuation.

\section{B. Response to Pole-to-Pole DC Faults}

To test the performance under a DC fault, a permanent DC pole-to-pole (PTP) fault is applied at $3 \mathrm{~s}$ at the head of the HTS cable $\left(F_{l}\right.$ in Fig. 1$)$, and the simulation results are shown in Fig. 14 and Fig. 15 .

Fig. 14 (a) and (b) show the DC pole voltages of the offshore and onshore stations, respectively. Since the fault is close to the offshore platform, the offshore DC pole voltages drop to zero quickly, leading to arm overcurrent and blocking of the MMCs. Since the HTS DC cables are quenched, the onshore DC pole voltages are maintained at $\pm 75 \mathrm{kV}$ under post-fault steady-state. Fig. 14 (c) shows the RMS voltage of the offshore AC network. Due to the WT converters operating at the current limiting mode, the RMS voltage drops to $36 \mathrm{kV}$. Fig. 14 (d) shows the

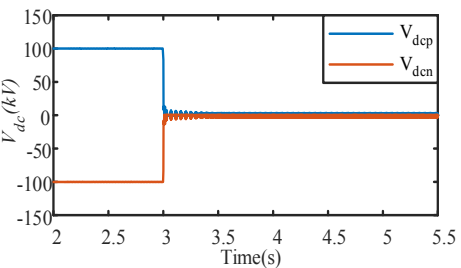

(a) pole voltages of offshore station

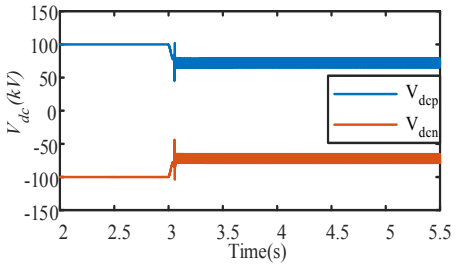

(b) pole voltages of onshore station

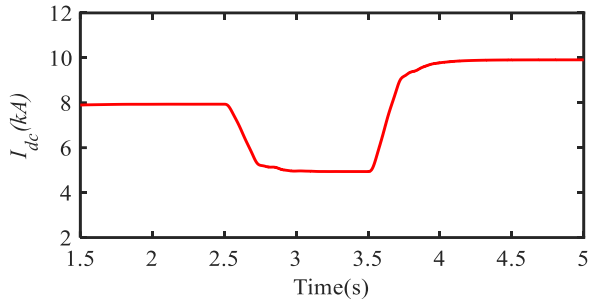

(c) DC cable current

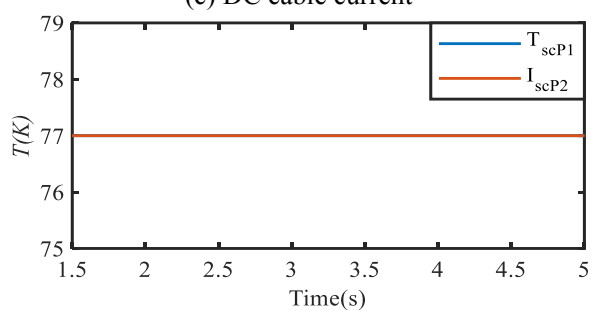

(f) SC temperatures

average SM capacitor voltage of the upper arm of phase A of $\mathrm{MMC1}$. As can be seen, the capacitor voltage stays unchanged once MMC1 is blocked.

Fig. 15 (a)-(c) show the DC cable currents, the HTS resistances and the SC temperatures of the two $\pi$ sections on the positive pole, respectively. As can be seen, once the DC cable current exceeds the critical current $(-18.05 \mathrm{kA})$, the SCs will enter the quenching state, leading to an increase of HTS resistances and temperatures. They are respectively maintained at $65 \Omega$ and $142 \mathrm{~K}$ during post-fault steady-state. Fig. 15 (d)-(f) show the DC cable currents, the HTS resistances and the SC temperatures of the two $\pi$ sections on the negative pole. Identical results can be observed compared to the counterparts on the positive pole.

(c) RMS voltage of PCC1

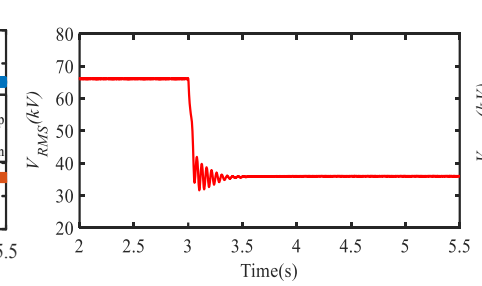

(d) Average SM voltage of upper arm of phase $\mathrm{A}$ of $\mathrm{MMC1}$

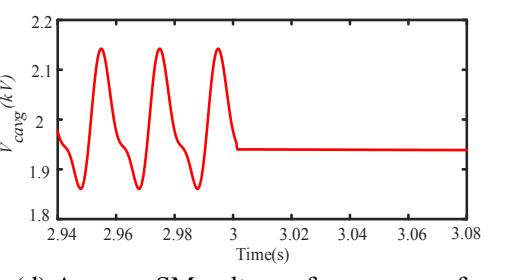

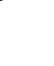

Fig. 14. HVDC system performance under a $F_{l}$ PTP fault.

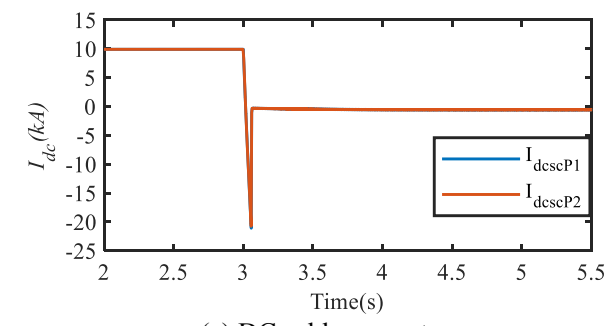

(a) DC cable current

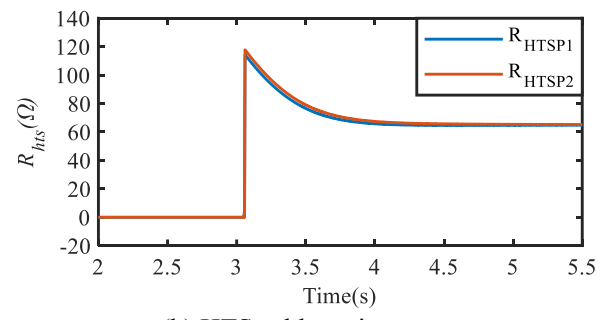

(b) HTS cable resistances

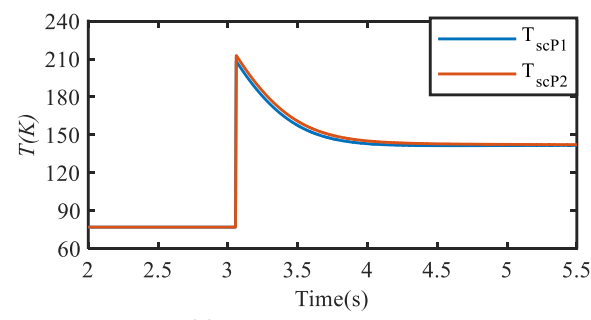

(c) SC temperatures 


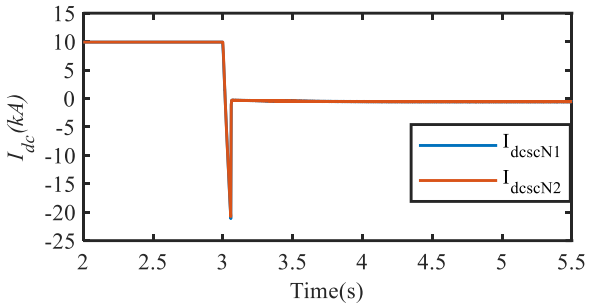

(d) DC cable current

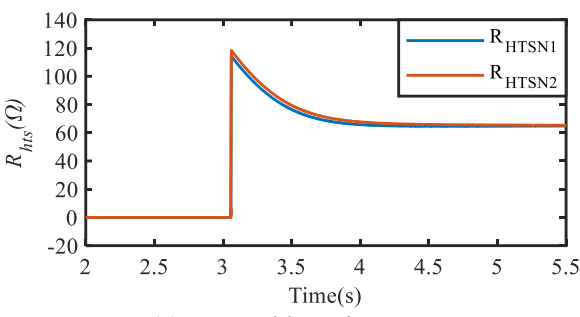

(e) HTS cable resistances

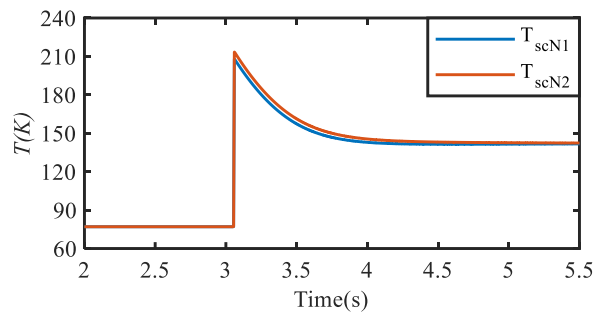

(f) SC temperatures

Fig. 15. Performance of HTS DC cables under a $F_{l}$ PTP fault.

To test the performance under a middle cable DC fault, a permanent DC pole-to-pole (PTP) fault is applied at $3 \mathrm{~s}$ at the middle of the HTS cable ( $F_{2}$ in Fig. 1). The simulation results under the $F_{2}$ fault are depicted in Fig. 16 and Fig. 17.

Fig. 16 (a)-(b) show the DC pole voltages of the offshore and onshore stations. Due to the quenching of SCs, the voltages are maintained at $\pm 81 \mathrm{kV}$ and $\pm 75 \mathrm{kV}$, respectively. Fig. 16 (c) shows the offshore wind power and the received active power of the onshore grid. Since the AC circuit breakers (ACCBs) are not tripped, the power has a very small value, which is mainly due to the HTS cable resistances and diode resistances of the MMCs. Fig. 16 (d) shows the PCC RMS voltage of the offshore AC network. Due to the saturation of WT controller, there is a slight increase ( $9 \%$ of the rated value) in the RMS voltage.

Fig. 17 (a)-(d) show the DC cable currents, the capacitor-toground currents ( $I_{c p 1}$ and $I_{c p 2}$ in Fig. 7), the HTS resistances and the SC temperatures of the two $\pi$ sections on the positive pole, respectively. When the middle line fault occurs, the DC cable current of the first $\pi$ section (which is close to the offshore station) will increase directly. In contrast, the second $\pi$ section (which is close to the onshore station) will decrease to zero at first, and then reversely increase. Thus, there is a difference in the arrival time of peak currents between the two sections, as can be seen in the zoomed-in waveform in Fig. 17 (a). On the other hand, the capacitor-to-ground (CTG) currents of the two $\pi$ sections are also different. These two aspects together make the DC cable currents of the two $\pi$ sections different from each other, resulting in a difference in HTS resistances and SC temperatures of the two $\pi$ sections, as shown in Fig. 17 (c)-(d).

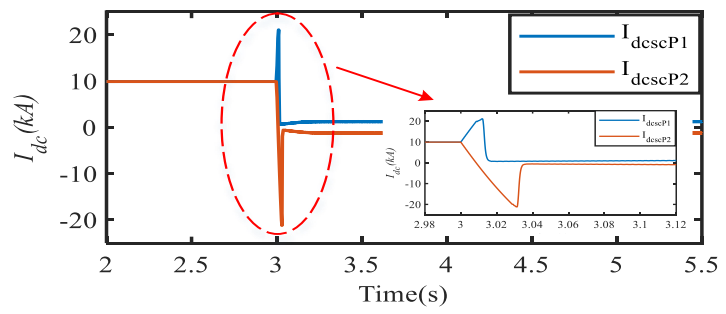

(a) DC cable current of the two sections of the positive pole

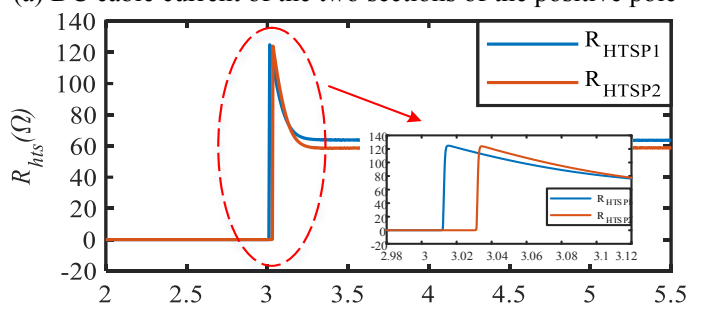

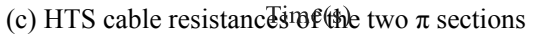

Fig. 17. HTS cable performance under a $F_{2}$ PTP fault.
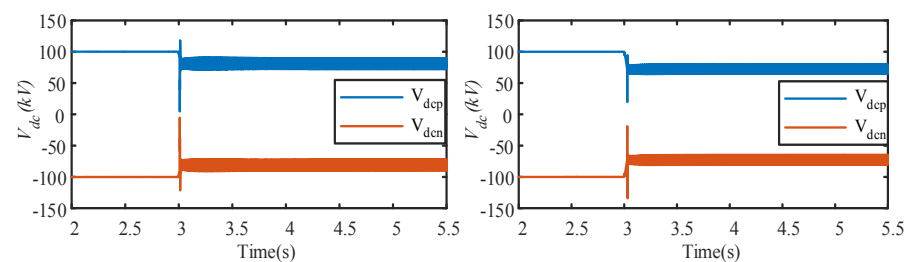

(a) pole voltages of offshore station

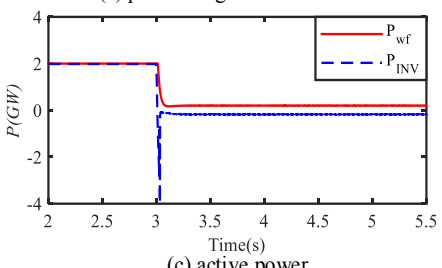

(c) active power

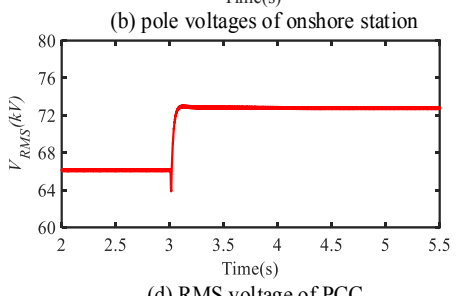

(d) RMS voltage of PCC

Fig. 16. HVDC system performance under a $F_{2}$ PTP fault.

\section{Performance under Pole-to-Ground Faults}

To test the performance under pole-to-ground (PTG) faults, a permanent positive PTG fault is applied at $3 \mathrm{~s}$ at the middle of the HTS cable $\left(F_{2}\right)$, and the simulation results are depicted in Fig. 18.

Fig. 18 (a)-(b) show the DC pole voltages of the offshore and onshore stations. Under PTG faults, the DC voltage controller can operate normally. Thus, the faulted pole voltages drop to zero while the pole voltages of the healthy pole increase to two times the rated value, as depicted in Fig. 18 (a)-(b). Since there is no overcurrent, the active power transmission is not interrupted and the RMS voltage of the offshore AC network is controlled at $66 \mathrm{kV}$, as depicted in Fig. 18 (c)-(d). Meanwhile, the SCs remain in superconducting states, as shown in Fig. 18 (e)-(f).

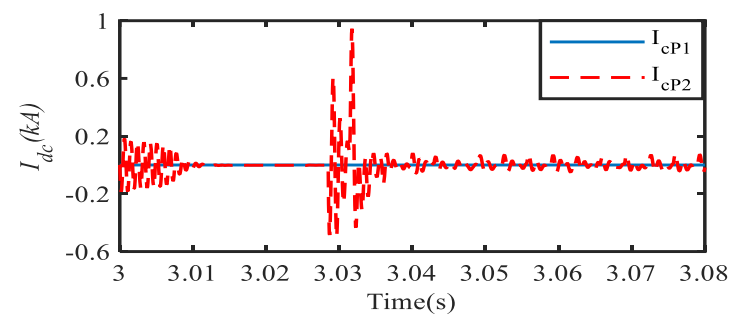

(b) CTG current of the two sections of the positive pole

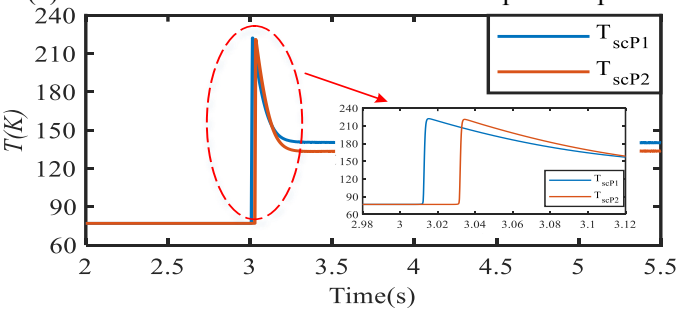

(d) SC temperatures of the two $\pi$ sections 


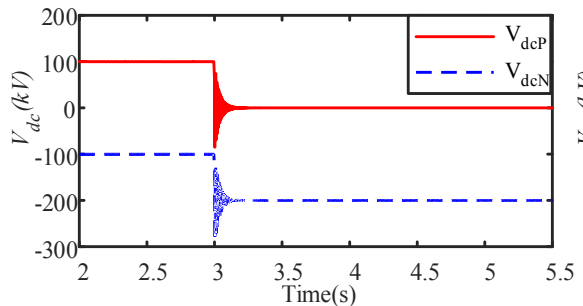

(a) pole voltages of offshore station

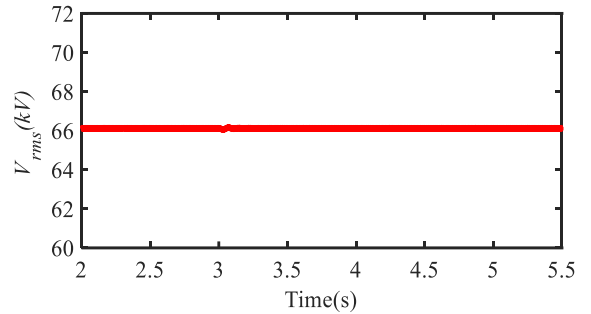

(d) RMS voltage of PCC1

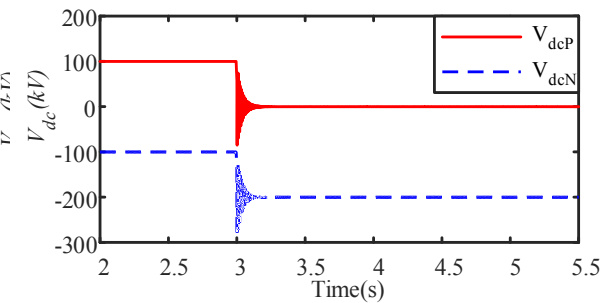

(b) pole voltages of onshore station

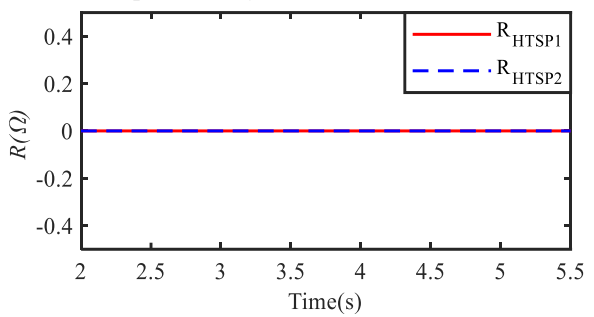

(e) HTS cable resistances

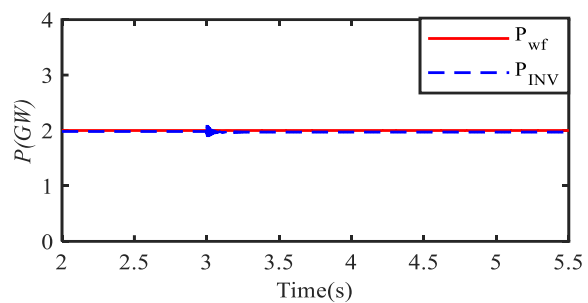

(c) active power

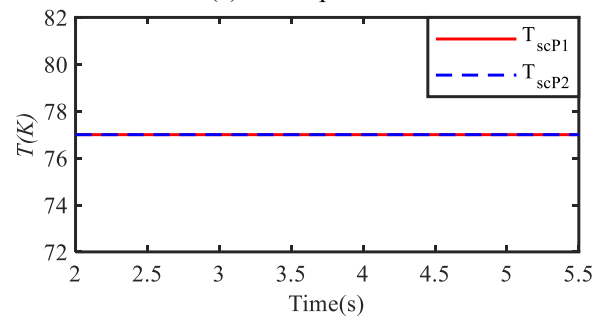

(f) SC temperatures of the two $\pi$ sections

Fig. 18. HVDC system performance under an $F_{2}$ PTG fault.

It can be concluded from Fig. 18 that the PTG faults will not cause an overcurrent problem, but bring about an overvoltage on the cables. In practice, such overvoltage will have to be curtailed and normal operation interrupted.

\section{Response to AC Grid faults}

To test the performance under AC faults, a temporary threephase to ground fault is applied at $F_{4}$ at 3 s. During the fault period, the grid side voltage drops to 0.7 p.u.. $100 \mathrm{~ms}$ later, the fault is self-cleared. The results are shown in Fig. 19.

Fig. 19 (a) shows the instantaneous voltages at PCC2. The voltages drop to 0.7 p.u. at 3 s. During the grid voltage sag, the surplus wind power will cause the increase of DC pole voltages and the fluctuation of DC cable current, as shown in Fig. 19 (b) and Fig. 19 (c), respectively. Since the cable currents are still below the critical current of HTS DC cables, the superconductors' temperatures remain at $77 \mathrm{~K}$. The superconducting state is not affected.

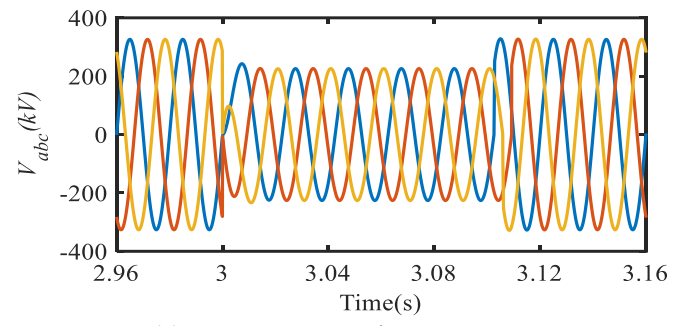

(a) Instantaneous voltages at PCC2

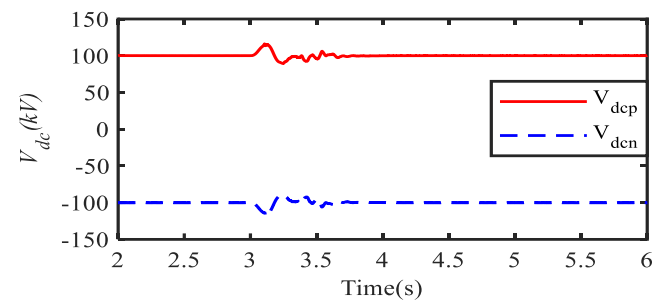

(b) Pole voltages of offshore station

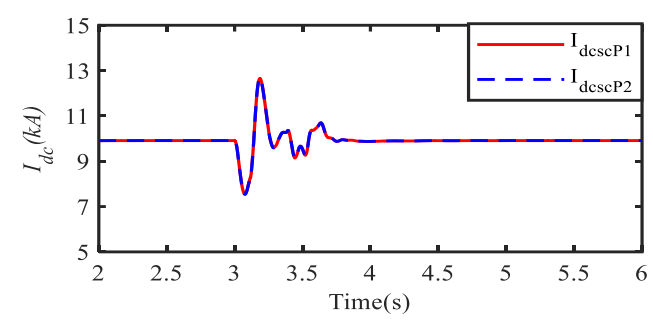

(c) DC currents of two $\pi$ sections of the positive DC cable

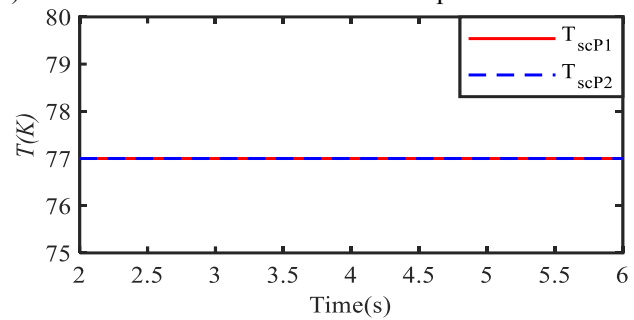

(d) SC temperatures of two $\pi$ sections of the positive DC cable

Fig. 19. Response to an $A C$ fault at grid side.

\section{E. Comparisons with Conventional HVDC Cable}

To compare the system's performance with that with conventional HVDC cables, the HTS cables shown in Fig. 1 are replaced by $100 \mathrm{~km}$ conventional extruded DC cables. The DC cable is modeled using the frequency-dependent phase model provided by PSCAD/EMTDC and its configuration is depicted in Fig. 20. Applying the same $F_{2}$ PTP fault as reported in Section IV.B, the simulation results are shown in Fig. 21.

Figs. 19 (a)-(b) show the DC pole voltages of the offshore and onshore stations, which drop to zero quickly after fault occurrence. Fig. 21 (c) shows the DC cable currents. As can be seen, the DC current of the onshore station increases to four times the rated value. Fig. 21 (d) shows the RMS voltage of PCC which drops to $44 \mathrm{kV}$ under post-fault steady-state. Comparing Fig. 17 (a) with Fig. 21 (c), it can be seen that the HTS DC cables can limit the fault current (less than 2 p.u.) due to the quenching of the SCs. Meanwhile, comparing Fig. 16 (a)(b) with Fig. 21 (a)(b), the pole voltages of the HTS cable case can be kept in a relatively high value, which helps to restore the HVDC system quicker. 


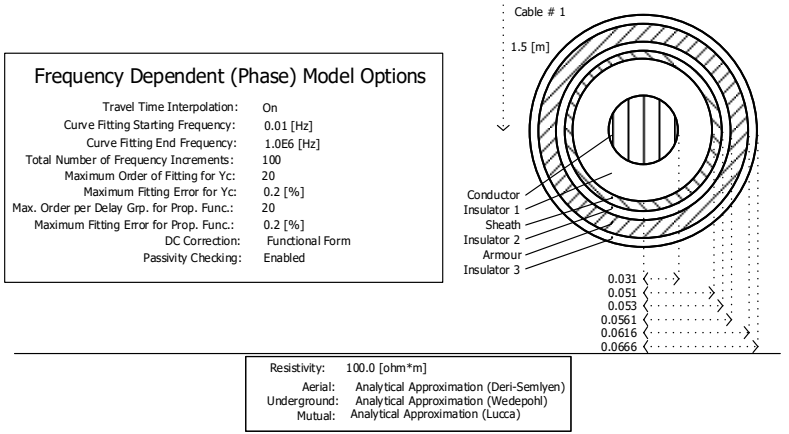

Fig. 20. Configuration of the conventional HVDC cable.

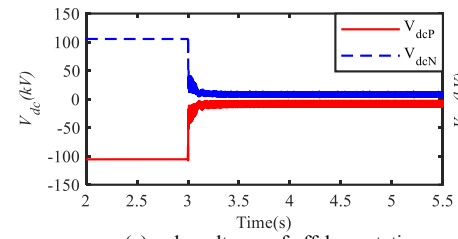

(a) pole voltages of offshore station

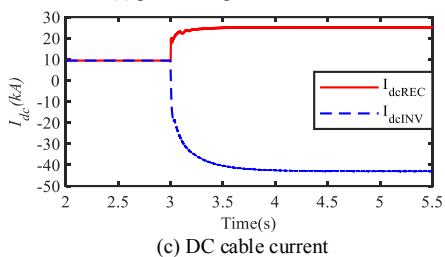

(c) DC cable current

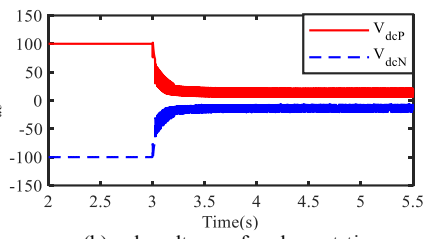

(b) pole voltages of onshore station

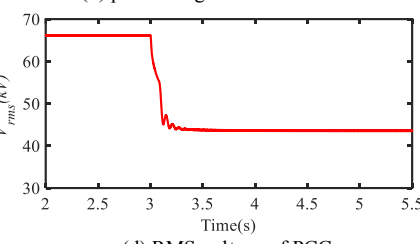

(d) RMS vol tage of PCC
Fig. 21. System performance using conventional DC cable under $F_{2}$ PTP faults.

\section{CONCLUSION}

In this paper, $\mathrm{a} \pm 100 \mathrm{kV} / 2 \mathrm{GW}$ point-to-point HVDC system using HTS DC cables is proposed to integrate large-scale offshore wind power. The multiple $\pi$-section based lumped HTS DC cable model with controllable input parameters is developed in PSCAD. The simulation results under temporary and permanent DC faults verify that the proposed lumped model can effectively simulate the quenching stage and that the two $\pi$-section lumped model is sufficiently accurate for power system studies.

Detailed fault transient studies of the OWF HVDC system with HTS DC cables are conducted. During pole-to-pole faults, the quenching of HTS DC cables provides a certain degree of protection against DC faults. The overcurrent is smaller than that seen when using conventional DC cables. During pole-toground faults, the DC cable current is lower than the critical current of the HTS DC cable, so quench does not occur. These results provide useful guidance for the operation and protection design for future HVDC and HTS DC cable systems.

Given their inherent fault protection properties in certain fault scenarios, HTS DC cables may facilitate the integration of more cost-effective protection systems when employed in a meshed DC grid. However, further work is required to establish the costs of various components of an offshore network utilizing HTS DC cables. Moreover, a developer would require confidence regarding the reliability of the system including the cable and its insulation, the cooling system and the terminations. And redundancy is needed for key elements. As yet, minimal operating experience is available to draw on, even for individual components, and demonstrator systems of sufficient scale will be required. As for the important cost- benefit analysis, the results using present-day best estimates will be presented in our future work.

\section{REFERENCES}

[1] W. Xiang, S. Yang, G. P. Adam, et al, "DC Fault Protection Algorithms of MMC HVDC Grids: Fault analysis, Methodologies, Experimental Validations and Future Trends," IEEE Tran. Power Electron., early access, to be published.

[2] W. Xiang, S. Yang, L. Xu, et al, "A Transient Voltage-Based DC Fault Line Protection Scheme for MMC-Based DC Grid Embedding DC Breakers," IEEE Trans Power Del., vol. 34, no. 1, pp. 334-345, Feb. 2019.

[3] K. Huang, W. Xiang, L. Xu and Y. Wang, "Hybrid AC/DC hub for integrating onshore wind power and interconnecting onshore and offshore DC networks," IET Renew. Power Gener., vol. 14, no. 10, pp. 1738-1745, Jul. 2020.

[4] Wikipedia, "List of HVDC projects," https://en.wikipedia.org/wiki/List_ of_HVDC_projects," accessed on 7 April 2021.

[5] C. A. Charalambous, "Interference Activity on Pipeline Systems from VSC-Based HVDC Cable Networks with Earth/Sea Return: An Insightful Review," IEEE Trans. Power Del., early access, to be published.

[6] M. Ardelean, P. Minnebo, "Extruded Cables for HVDC Power Transmission HVDC Submarine Power Cables in the World," JRC Technical report.

[7] DNV GL, The National HVDC Centre and EPNC, Holistic Approach to Offshore Transmission Planning in Great Britain, report for National Grid ESO, November 2020.

[8] Y. Liu, J. Ou, F. Schreiner, M. Lao, M. Noe and M. Doppelbauer, "Design of a Superconducting DC Demonstrator for Wind Generators," IEEE Trans. Energy Convers., vol. 33, no. 4, pp. 1955-1964, Dec. 2018.

[9] A. M. Gee, F. Robinson and W. Yuan, "A Superconducting Magnetic Energy Storage-Emulator/Battery Supported Dynamic Voltage Restorer," IEEE Trans. Energy Convers., vol. 32, no. 1, pp. 55-64, March 2017.

[10] Z. Zhang, "Electrical characterizing of superconducting power cable consisted of second-generation high-temperature superconducting tapes," Phd thesis, University of Bath, 2016.

[11] M. C. Dinh, C. H. Ju, J. G. Kim, et al, "Transient analysis of an HTS DC power cable with an HVDC system," Physica C: Supercond. and its Applic., vol. 494, pp. 311-318, 2013.

[12] B. Yang, J. Kang, S. Lee, C. Choi and Y. Moon, "Qualification Test of a $80 \mathrm{kV} 500 \mathrm{MW}$ HTS DC Cable for Applying Into Real Grid," IEEE Trans. Appl. Supercond., vol. 25, no. 3, pp. 1-5, Jun. 2015.

[13] Z. H. Chen, J. X. Jin, L. H. Zheng and Z. H. Wu, "Advanced HTS DC Transmission with Self-Protection Function," IEEE Trans. Appl. Supercond., vol. 26, no. 7, pp. 1-5, Oct. 2016.

[14] M. C. Dinh, C. Ju, S. Kim, et. al, "Performance analysis of a model-sized superconducting DC transmission system based VSC-HVDC transmission technologies using RTDS," Physica C: Supercond. and its Applic., vol. 478, pp. 10-14, 2012.

[15] D. I. Doukas, A. Syrpas and D. P. Labridis, "Multi terminal DC Transmission Systems Based on Superconducting Cables Feasibility Study, Modeling, and Control," IEEE Trans. Appl. Supercond., vol. 28, no. 4, pp. 1-6, Jun. 2018.

[16] A. Morandi, B. Gholizad, M. Stieneker, H. Stagge and R. W. De Doncker, "Technical and Economical Evaluation of DC High-Temperature Superconductor Solutions for the Grid Connection of Offshore Wind Parks," IEEE Trans. Appl. Supercond., vol. 26, no. 6, pp. 1-10, Sept. 2016.

[17] A. Ballarino, C. E. Bruzek, N. Dittmar, et. al., "The BEST PATHS Project on MgB2 Superconducting Cables for Very High Power Transmission," IEEE Trans. Appl. Supercond., vol. 26, no. 3, pp. 1-6, April 2016.

[18] H. Saad, J. Peralta, S. Dennetiere, et al., "Dynamic Averaged and Simplified Models for MMC-Based HVDC Transmission Systems," IEEE Trans. Power Del., vol. 28, no. 3, pp. 1723-1730, Jul. 2013.

[19] W. Xiang, et al, "Equivalent Electromagnetic Transient Simulation Model and Fast Recovery Control of Overhead VSC-HVDC Based on SBMMC," IEEE Trans. Power Del., vol. 32, no. 2, pp. 778-788, Apr. 2017.

[20] H. Saad, S. Dennetière, J. Mahseredjian, et al., "Modular Multilevel Converter Models for Electromagnetic Transients," IEEE Trans. Power Del., vol. 29, no. 3, pp. 1481-1489, June 2014.

[21] L. Rostila, L. Soderlund, R. Mikkonen, J. Lehtonen, "Modelling method for critical current of YBCO tapes in cable use," Physica C: Supercond. and its Applic., vol. 467, no. 1/2, pp. 91-95, Dec. 2007.

[22] T. Jin, J. Hong, H. Zheng, et al., "Measurement of boiling heat transfer 
coefficient in liquid nitrogen bath by inverse heat conduction method," $J$. Zhejiang Univ. Sci. A, vol. 10, pp. 691-696, 2009.

[23] M. Elshiekh, M. Zhang, H. Ravindra, et al., "Effectiveness of Superconducting Fault Current Limiting Transformers in Power Systems," IEEE Trans. Appl. Supercond., vol. 28, no. 3, pp. 1-7, Apr. 2018.

[24] R. Inoue, D. Miyagi, M. Tsuda and H. i. Matsuki, "Magnetization Loss Characteristics of a GdBCO Tape in kHz Frequency Band," IEEE Trans. Appl. Supercond., vol. 28, no. 4, pp. 1-5, Jun. 2018.

[25] L. Cheng, H. Feng, Y. Chang and C. Singh, "Reliability Analysis of HTS Cable Systems," IEEE Trans. Power Del., vol. 30, no. 3, pp. 1251-1259, Jun. 2015.

[26] S. Klöppel, A. Marian, C. Haberstroh, C. E. Bruzek, "Thermo-hydraulic and economic aspects of long-length high-power MgB2 superconducting cables," Cryogenics, vol. 113, 2021, 103211.

\section{BIOGRAPHIES}

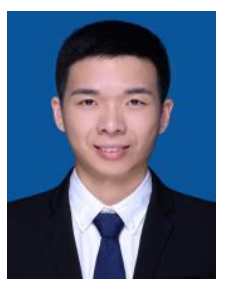

Wang Xiang (S'16-M'17) received his B.Eng. and $\mathrm{PhD}$ degrees both in electrical engineering from Huazhong University of Science and Technology (HUST), China in 2012 and 2017 respectively. He was a visiting Phd student at the University of Aberdeen and the University of Strathclyde in 2014 and 2016 respectively. He joined the University of Strathclyde in 2018 and currently is a research associate. His main research interests include MMC-HVDC, high power dc/dc converters and dc grids.

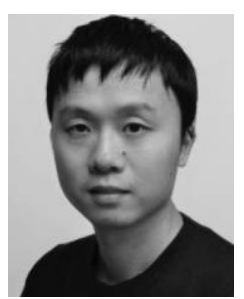

Weijia Yuan (SM'18) received the bachelor's degree from Tsinghua University and the Ph.D. degree from the University of Cambridge. He was a Research Associate with the Engineering Department, University of Cambridge, and a Junior Research Fellow with the Wolfson College, University of Cambridge. He joined the University of Bath, as a Lecturer/Assistant Professor, in 2011, where he was later promoted to a Reader/Associate Professor, in 2016. He joined the University of Strathclyde, as a Professor, in 2018. He is currently leading a research team of more than ten members in the area applied superconductivity including energy storage, fault current limiters, machines and power transmission lines. His work also involves renewable energy integration and electrical propulsion technologies for transportation

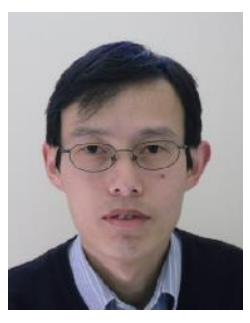

Lie Xu (M'03-SM'06) received the B.Sc. degree in mechatronics from Zhejiang University, Hangzhou, China, in 1993, and the Ph.D. degree in electrical engineering from the University of Sheffield, U.K., in 1999. He is currently a Professor at the Department of Electronic and Electrical Engineering, University of Strathclyde, Glasgow, U.K. He previously worked in ALSTOM T\&D, Stafford and Queen's University of Belfast, U.K. His research interests include power electronics, wind energy generation and grid integration, and application of power electronics to power systems.

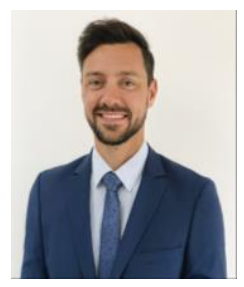

Eoin Hodge received his MEng in mechanical engineering from the Munster Technical University, Ireland, in 2004, and a PhD in Electrical Engineering from the University of Wollongong, Australia, in 2018. $\mathrm{He}$ has extensive experience developing advanced technologies in renewables generation $\mathrm{R} \& \mathrm{D}$, machine engineering, power systems integration, offshore engineering, and transmission products. His research interests include power systems engineering, generation and transmission product development.

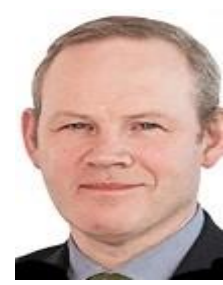

John Fitzgerald is the CEO of SuperNode Ltd, a company developing innovative cryostat technology to extend the range and use case for superconductors. John has extensive experience of power systems and grid infrastructure. He was the Director of Grid Development \& Interconnection with EirGrid, the Irish TSO, with responsibility for all onshore transmission and the development and operation of Interconnection. Prior to this, John was Project Director of the East West Interconnector, directly connecting the electricity markets of Ireland and Britain for the first time in 2012 with, what was then, the largest HVDC scheme of its kind in the World.

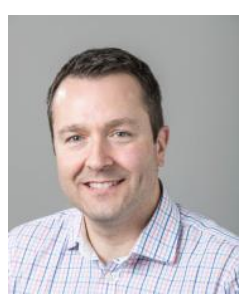

Paul McKeever obtained his Masters Degree (MEng/BEng (Hons)) in Electrical and Electronic Engineering from the University of Bradford, Bradford, U.K.. He joined ORE Catapult (formerly Narec) in August 2006 and currently holds the post of Head of Electrical Research. Prior to ORE Catapult, Paul spent sixteen years in the automotive and railway industries in Project Engineer, Lead Engineer and Technical Team Leader roles. His research team is responsible for the delivery of an electrical research programme ranging from wind turbine components to energy system/electrical infrastructure solutions. He is a Member of the Institution of Engineering and Technology (MIET) and a Chartered Engineer (CEng). He currently holds Board and ExCo positions with the European Association of Renewable Energy Research Centres (EUREC), the European Energy Research Alliance Joint Programme for Wind (EERA JPWind) and the European Technology and Innovation Platform for Wind (ETIPWind). He also chairs the Industrial Advisory Board for the SuperGen ORE Hub research programme.

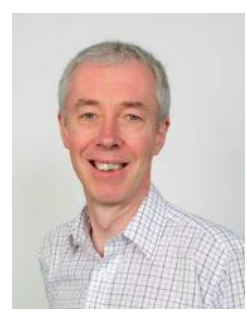

Keith Bell received the B.Eng. (Hons) and Ph.D. in electrical engineering from the University of Bath, Bath, U.K., in 1990 and 1995, respectively. He holds the Scottish Power Chair in Smart Grids at the University of Strathclyde and is a Co-Director of the UK Energy Research Centre (UKERC), one of two Scientific Directors of the Electrical Infrastructure Research Hub with the ORE Catapult and University of Manchester, a Fellow of the Royal Society of Edinburgh, a member of the UK's Climate Change Committee and a Chartered Engineer. Before joining Strathclyde, he worked as a system development planner in the electricity supply industry in England and as a researcher in Bath, Naples and Manchester. He is active in CIGRE and has provided advice on power systems issues to parties including the Scottish Government, the Office of Gas and Electricity Markets (Ofgem) in Britain, the UK Government and the Government of Ireland. 